OPEN ACCESS

Edited by:

Cheng Zhong,

Tianjin University, China

Reviewed by:

MouCheng Li,

Shanghai University, China

Tao Liu,

Shanghai Maritime University, China

*Correspondence:

Yangting Sun

sunyangting@fudan.edu.cn

Jin $\mathrm{Li}$

jinli@fudan.edu.cn

Specialty section:

This article was submitted to

Electrochemistry,

a section of the journal

Frontiers in Chemistry

Received: 27 April 2020

Accepted: 22 May 2020

Published: 24 June 2020

Citation:

Wan Y, Sun Y, Cai D, Yin L, Dai N, Lei L, Jiang Y and Li J (2020) Influence of Ethanol on Pitting Corrosion

Behavior of Stainless Steel for Bioethanol Fermentation Tanks.

Front. Chem. 8:529.

doi: 10.3389/fchem.2020.00529

\section{Influence of Ethanol on Pitting Corrosion Behavior of Stainless Steel for Bioethanol Fermentation Tanks}

\author{
Yiting Wan ${ }^{1}$, Yangting Sun ${ }^{1 *}$, Dingzhou Cai ${ }^{2}$, Liqiang Yin ${ }^{1}$, Nianwei Dai ${ }^{1}$, Longlin Lei ${ }^{1}$, \\ Yiming Jiang ${ }^{1}$ and $\mathrm{Jin}^{\mathrm{Li}}{ }^{1 *}$ \\ ${ }^{1}$ Corrosion Lab, Department of Materials Science, Fudan University, Shanghai, China, ${ }^{2}$ Institute of Materials, China Academy \\ of Engineering Physics, Mianyang, China
}

The role of ethanol $\left(\mathrm{C}_{2} \mathrm{H}_{5} \mathrm{OH}\right)$ in pitting corrosion behavior of AISI 316L austenitic stainless steel was investigated in aqueous ethanolic solution with chloride. The pitting susceptibility and surface morphology of $316 \mathrm{~L}$ in a series of ethanol-containing solutions were examined using X-ray photoelectron spectroscopy (XPS), optical microscopy with 3D stitching, immersion tests, and potentiodynamic polarization measurements. Results demonstrated that the ethanol concentration impacted little on the passive film stability while it dramatically influenced the pitting corrosion susceptibility. Corrosion rate of $316 \mathrm{~L}$ after immersion tests first increased and then decreased as the concentration of ethanol increased from 0 to $10 \mathrm{M}$ in ferric chloride solution. This, however, did not correspond to the breakdown potential which directly decreased from 489 to $249 \mathrm{mV}$ as the water concentration decreased in ethanolic $\mathrm{NaCl}$ solutions. The pits density after both immersion and electrochemical tests showed that the initiation of pitting in ethanolic solution tended to occur at multiple points at the same time. The synergy effect on pitting behavior of hydrolysis enhancement and solubility reduction of metal cations due to the introduction of ethanol has also been discussed.

Keywords: stainless steel, ethanolic solutions, pitting corrosion, potentiodynamic polarization, morphology

\section{INTRODUCTION}

Bioethanol has been widely recognized as a promising renewable sustainable biofuel to replace diminishing petroleum-based fuel in existing combustion motor system. Regular crops such as corn and sugarcane, due to their chief value in food reserves, are unable to meet the increasing worldwide demand of fuel-grade ethanol. Thus, agriculture wastes, particularly lignocellulosic biomass like straw and microalgae, with competitive cost and abundant stock are potential raw materials for bioethanol. The key factor for gradual replacement of feedstocks is to adjust production process owing to different degradability of sugar, starch, and cellulose. With almost the same process flow, lignocellulosic ethanol production differs a lot on pre-treatment and fermentation. Lignocellulosic ethanol production prefers acid-based methods in one-step fermentation process to enzyme-cocktail based methods, which is commonly used in crop-based ethanol production but introduces fewer corrosive contaminants such as chlorides and sulfuric acid (Sarkar et al., 2012). Currently, some lignocellulosic ethanol is still fermented in traditional vessels designed for cropbased bioethanol focusing on mechanical strength but not on corrosion resistance (Torsner, 2010). Before the biological fermentation methods become the best choice, various corrosion problems, 
such as pitting, crevice corrosion, and stress corrosion crack, still exist in ethanol production process. For fear of corrosion accident in bioethanol production, coating was suggested to prevent corrosion of steels in ethanolic environment (Radi et al., 2019). Coating is a widely used method to enhance corrosion resistance. Blunt materials such as epoxy (Bisht et al., 2017), graphite (Wang et al., 2019), alumina (Sun et al., 2019), and polyaniline (Lei et al., 2020) are often recommended. However, there are still many difficulties in using this method in large tanks. Therefore, it is necessary to study the corrosion behavior of traditional stainless steel for bioethanol fermentation tanks, such as AISI 316L stainless steel, which is still widely used in the production of bioethanol, in ethanolic solutions.

Some research works have been done to understand corrosion behavior of metals in various organic media (Ekilik and Grigor'ev, 2002; Newman, 2008; Soriano and Alfantazi, 2016). Organic type (Hronsky, 1981), solution viscosity (Samide et al., 2015), water content (Calabrese et al., 2018), and pH (Kahyarian et al., 2017) could be the main factors that influence the passivation and corrosion behavior of metals. Due to specificity and importance of methanol in chemical industry, numerous studies concentrated on methanolic systems (Wang et al., 2007, 2016; Hu et al., 2012). Discussion on this issue tended to ascribe localized corrosion of stainless steels in methanolic solution to deterioration of passive film and diffusion rate drop with the higher viscosity of methanol (Ekilik and Grigor'ev, 2002). Pitting potential of stainless steels was regarded as a function of water content in methanol/ $\mathrm{HCl}$ since the formation of passive layer depends on water activity (Hronsky and Duquette, 1982). Some researches postulated that passivation of stainless steel would fail in anhydrous solutions with water less than 70 mole \% (Kelly and Moran, 1990). In addition to the influence of methanol on passive film, dissolution kinetics in pits were activated with increasing water concentration in methanol/ $\mathrm{NaCl}$ at a given potential (Ramgopal and Amancherla, 2012).

In last 10 years, focus shifted from corrosion behavior of metals in methanolic solution to stress corrosion cracking (SCC) and pitting corrosion of carbon steels and stainless steels in simulated fuel grade ethanol (SFGE) (Gui et al., 2010; Lou et al., 2010; Beavers et al., 2011; Samusawa and Shiotani, 2015; Torkkeli et al., 2015) to clarify reliability of pipelines in transportation of bioethanol with minor impurities such as water and chloride. Chlorides, $\mathrm{pH}$, inclusions, temperature even trace water were found that have obvious effect on SCC and pitting susceptibility in SFGE. Study on this issue paid more attention on the impact of trace impurities on corrosion behavior. Iron (II) acetate, which showed strong solubility in FGE and introduced by acetic acid impurities, was unearthed aggravating the passivation of carbon steel with Raman spectra (Samusawa and Shiotani, 2015). Longterm exposure tests in fuel-grade ethanol (Lou and Singh, 2010) showed that pitting susceptibility of carbon steels increased as the water content (below 5 vol.\%) increases while water content more than 10 vol.\% reduced pitting corrosion.

Limited research reminded that change in the ethanolic solution chemistry could play a crucial role in the localized corrosion of stainless steel. Some work introduced that typical pitting corrosion only occurred in 20 (v/v\%) bioethanol SFGE with certain concentration of trace water (Abel and Virtanen, 2015). Ethanol, as an inefficient hydrotropic agent for water and gasoline, induced water and $\mathrm{Cl}^{-}$to enrich on the surface of matrix. It is noteworthy that the precipitation $\mathrm{pH}$ of nickel hydroxide would decrease as the concentration of ethanol increases, which makes hydrolysis of $\mathrm{Ni}^{2+}$ more intense (Ho and Van Zee, 2000). While researches in SFGE discussed the effect of water on corrosion behavior, inadequate studies have addressed the localized corrosion behavior of stainless steels in solutions with less than 30 mole \% ethanol content, which is more suitable for digging out the influence of ethanol. Otherwise, a common defect of experiment in researches in low-ethanolcontent solutions is the use of mass fractions as the unit for concentration of contents, which causes the fluctuation activity of contents like chloride since the density of solutions differs with the concentration of ethanol. Ferreira et al. recorded the electrochemical impede spectra (EIS) of 316L in 1 wt.\% $\mathrm{H}_{2} \mathrm{SO}_{4}$ and $0.35 \mathrm{wt} . \% \mathrm{NaCl}$ solutions with and without ethanol to prove that the passive film of stainless steel was decayed by ethanol (Ferreira et al., 2013), which should have been the influence of the higher effective concentration of $\mathrm{H}^{+}$and $\mathrm{Cl}^{-}$.

In the present work, pitting behavior and surface morphology of AISI 316L stainless steel, the material widespread in bioethanol fermentation (Rocha et al., 2012; Lee et al., 2013), is investigated. Since the passivation of stainless steel would fail in anhydrous solutions with water less than 70 mole \% (Kelly and Moran, 1990), solutions with ethanol content from 0 to $10 \mathrm{M}$ were applied to ensure that changes of corrosion resistance are not caused by extremely low water content, The goal of the work is to clarify the influence of ethanol on passivation, pitting sensitivity and pits morphology. The results proved that the passive film on stainless steel was slightly deteriorated. At the same time, pitting resistance of 316L was severely aggravated even with a spot of ethanol. The relationships between hydrolysis and solubility of metal cations in ethanol and pits pattern are also discussed.

\section{EXPERIMENTAL}

\section{Specimens Preparation}

Samples used in this work were 316L austenitic stainless steel provided by Baoshan Iron \& Steel Co Ltd. The chemical composition of the steel is listed in Table 1. Before testing, the as-received samples were machined into large ones $(20 \times 30 \times$ $3 \mathrm{~mm})$ and small ones $(12 \times 12 \times 3 \mathrm{~mm})$ for chemical immersion tests and electrochemical measurements, respectively. The small samples for electrochemical measurements were mounted with epoxy resin to expose only front surface of specimen for testing. Before testing, all the specimens were ground with $\mathrm{SiC}$ papers gradually from 180 to 2,000 grit, polished with diamond polishing powder in $2.5 \mu \mathrm{m}$, rinsed with distilled water, degreased with ethanol and dried in blowing air. After then, the epoxy-sealed specimens were covered with perforated insulating tapes $(3 \mathrm{M}$ 7413D High Temperature Polyimide Tape) to set testing area to $1 \mathrm{~cm}^{2}$. All tests were operated just after normalized preparation process to ensure all the specimens were under the same status. 
TABLE 1 | Chemical compositions of as received 316 L stainless steel.

\begin{tabular}{|c|c|c|c|c|c|c|c|c|c|c|c|}
\hline Element & C & $\mathrm{Si}$ & Mn & $\mathbf{P}$ & $\mathbf{S}$ & $\mathrm{Cr}$ & $\mathrm{Ni}$ & $\mathrm{Cu}$ & $\mathbf{N}$ & Mo & $\mathrm{Fe}$ \\
\hline wt.\% & 0.021 & 0.46 & 1.37 & 0.034 & 0.001 & 16.39 & 10.21 & 0.16 & 0.034 & 2.03 & Bal. \\
\hline
\end{tabular}

\section{Immersion Tests}

The immersion tests started with measuring the weight and size of the samples. The approximate molar concentrations of the solution component used in ferric chloride pitting test in ASTM G48-03 (Designation, 2009) was applied to reduce the content difference caused by the density drop with the increase of ethanol. The samples were immersed at $30^{\circ} \mathrm{C}$ for $24 \mathrm{~h}$ in $0.3 \mathrm{M} \mathrm{FeCl}_{3}+$ $0.4 \mathrm{M} \mathrm{HCl}$ solutions with $0,1,2,5$, or $10 \mathrm{M}$ ethanol, respectively. For each solution, three samples were tested at the same time to ensure data repeatability. Since metal cations have different solubility in ethanolic and non-ethanolic solutions, the volumes of solutions were large enough to keep the metal cations dissolved from precipitation during tests. Once the immersion expired and all the samples rinsed with distilled water and dried in blowing air, samples were weighed, and the corrosion rates $\left(R_{c}\right)$ were calculated using the expression as followed:

$$
R_{c}=\frac{\Delta m}{S \cdot t}
$$

where $\Delta m$ is the weight loss of the sample, $S$ is the initial surface area of samples, and $t$ is the immersion time.

\section{Electrochemical Measurements}

The electrochemical tests were performed under $30^{\circ} \mathrm{C}$ in $1 \mathrm{M}$ $\mathrm{NaCl}$ solutions with $0,1,2,5$, or $10 \mathrm{M}$ ethanol. A special threeelectrode cell with a platinum counter electrode and a saturated calomel electrode (SCE) as the reference electrode was applied. All the potentials in electrochemical measurements were referred to SCE in this paper if not explicitly defined. O-ring was used to fix the electrodes into the cell to ensure the ethanol not to escape from the system during tests. Since the solubility of oxygen differs in ethanolic solution and in non-ethanolic solution, test solutions were infused with $\mathrm{N}_{2}$ gas before the tests for $30 \mathrm{~min}$ to adjust the oxygen dissolved in solutions to a close level for each electrochemical test.

Prior to the potentiodynamic polarization tests, cathodic polarization preconditioning under $-900 \mathrm{mV}$ for $2 \mathrm{~min}$ was conducted to samples. Then, the samples were stabilized at open circuit for $30 \mathrm{~min}$. The polarization scans were performed at $0.6 \mathrm{~V} \mathrm{~h}^{-1}$, starting at $-250 \mathrm{mV}$ below the corrosion potential, scanning toward positive potential, until the response current reached $100 \mu \mathrm{A} \mathrm{cm}^{-2}$ or $1 \mathrm{~mA} \mathrm{~cm}{ }^{-2}$ according to demand. The pitting potential $\left(E_{p}\right)$ is defined as the given potential at which the current density reaches $100 \mu \mathrm{A} \mathrm{cm}{ }^{-2}$. Since the solution resistivity differs with the concentration of ethanol, the actual potentials of working electrode were corrected with automatic IR compensation offered by the electrochemical workstation. After the measurements, the surface of the sample was slowly cleaned with deionized water, and then dehydrated in an electric drying oven to reduce the damage to the surface morphology of the sample.

\section{X-Ray Photoelectron Spectroscopy (XPS) Characterization}

XPS spectra were recorded by a PHI5300 instrument with a $14-\mathrm{kV}$ monochromatic $\mathrm{Mg}$ radiation source to determine the chemical compositions of the passive films of 316L samples. Since whether the passive film differs a lot in non-ethanolic and ethanolic solutions is the point, the electrolytes used to grow up the passive films were $0.02 \mathrm{M} \mathrm{H}_{3} \mathrm{BO}_{3}+0.005 \mathrm{M} \mathrm{Na}_{2} \mathrm{~B}_{4} \mathrm{O}_{7}$. $10 \mathrm{H}_{2} \mathrm{O}$ borate buffer solutions with or without $5 \mathrm{M}$ ethanol. To ensure the same initial condition, the working electrode was first cathodically polarized at $-0.9 \mathrm{~V}$ for $5 \mathrm{~min}$ in test solutions. Before the XPS characterization, specimens were stabilized at OCP for $4 \mathrm{~h}$. Just after the stabilization process, XPS spectra was taken. XPS data were fitted to determine the type and concentration of compounds in the films using Avantage software.

\section{Morphology Characterization}

A single lens reflex camera was used to record the surface morphology of samples after immersion tests. Surface morphology of samples after electrochemical tests was depicted using an optical microscope (DMM-400C). 3D profile of pits was examined with a 3D microscope with super wide depth of field (VHX-1000). The luminance of the output images from under focus to over focus was interpreted as depth and then stitched into the $3 \mathrm{D}$ plots. A circline shadowless lamp was introduced to reduce the pit depth error caused by the different convergence of light at the bottom of pits.

All the pits were counted with particle analysis function in ImageJ after fixed threshold binary processing.

\section{RESULTS}

\section{Chemical Composition of Passive Films}

XPS was employed to clear up how ethanol influences the quality of the passive films on 316L samples. Figures 1A,B shows the high-resolution $\mathrm{Cr} 2 \mathrm{p}_{3 / 2}$ XPS spectra of 316L samples stabilized in borate buffer solutions with $0 \mathrm{M}$ ethanol and $5 \mathrm{M}$ ethanol, respectively. The area fractions (\%Area) are also given for different chemical states of chromium and iron atoms. Three peaks are present in the $\mathrm{Cr} 2 \mathrm{p}_{3 / 2}$ spectra, including the $\mathrm{Cr}_{\text {met }}$ $(573.1 \mathrm{eV}), \mathrm{Cr}_{2} \mathrm{O}_{3}(576.0 \mathrm{eV})$, and $\mathrm{Cr}(\mathrm{OH})_{3}(577.2 \mathrm{eV})$. The area fraction of $\mathrm{Cr}_{2} \mathrm{O}_{3}$ was higher in ethanolic solutions while the area fraction of $\mathrm{Cr}(\mathrm{OH})_{3}$ was lower, which could be ascribed to the reduction of water content.

In the $\mathrm{Fe} 2 \mathrm{p}_{3 / 2}$ spectra in Figures 1C,D, $\mathrm{Fe}_{\text {met }}(706.0 \mathrm{eV}), \mathrm{FeO}$ $(708.5 \mathrm{eV})$, and $\mathrm{Fe}_{2} \mathrm{O}_{3}(710.0 \mathrm{eV})$ are present. Since the absence of ethanol in the oxidation-reduction reaction of metal oxides, the 

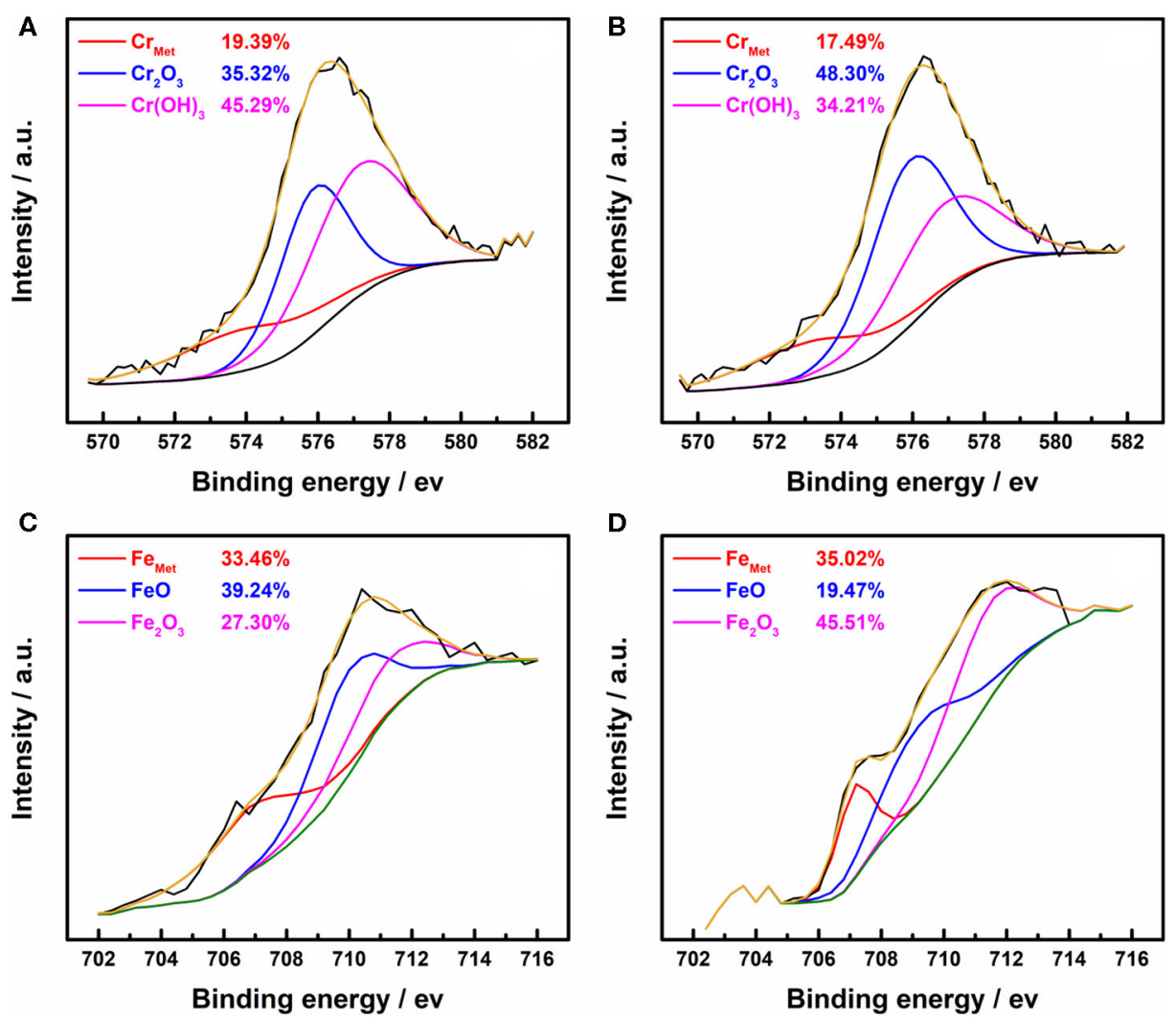

FIGURE 1 | High-resolution XPS spectra of the passive film formed on the $316 \mathrm{~L}$ specimens in borate buffer solutions. (A) $\mathrm{Cr} 2 \mathrm{p}_{3 / 2}$ in $0 \mathrm{M}$ ethanol, (B) $\mathrm{Cr} 2 \mathrm{p}_{3 / 2}$ in $5 \mathrm{M}$ ethanol, (C) Fe 2 $\mathrm{p}_{3 / 2}$ in $0 \mathrm{M}$ ethanol, (D) Fe 2 $\mathrm{p}_{3 / 2}$ in $5 \mathrm{M}$ ethanol.

area fraction of metal elements does not change significantly. The higher ferric oxide content may be due to the higher solubility of oxygen in the alcohol-containing solution (Shchukarev and Tolmacheva, 1968). As a result, iron oxides with high oxidation states were generated, even if the difference of partial pressure of oxygen was balanced by infusing $\mathrm{N}_{2}$ gas.

The atomic contents of the metal oxides, hydroxides species in the passive films of the $316 \mathrm{~L}$ stainless steel samples have been calculated and summarized in Table 2. For comparison purposes, the total atomic amount of the $\mathrm{Cr}, \mathrm{Fe}$, and $\mathrm{O}$ elements has been naturalized to 100 at.\%. It shows that when the water content is high, the total content of the metal oxides and metal hydroxide changed slightly. Since the content of metal oxides is the main factor of passivation (Okamoto and Shibata, 1970; Saito et al., 1979), the influence of ethanol on the performance of passive film is limited. The result fits to the passivation behavior of stainless steel in low-ethanol-content solutions in the potentiodynamic polarization test (de Anna, 1985).

\section{Effect of Ethanol on Pitting Behavior in Immersion Tests}

The corrosion rate of $316 \mathrm{~L}$ samples in acid ferric chloride solution with different ethanol concentrations is shown as Figure 2. With the increase of ethanol concentration, the corrosion rate of $316 \mathrm{~L}$ samples first increased then decreased,
TABLE 2 | Contents of the total metal oxides and metal hydroxides species in the passive films of 316L stainless steel samples calculated from XPS spectra fitting (at. \%).

\begin{tabular}{lcc}
\hline Ethanol concentration & $\mathbf{0 ~ M}$ & $\mathbf{5 ~ M}$ \\
\hline Total metal oxide & 10.10 & 10.99 \\
Total metal hydroxide & 4.40 & 3.96
\end{tabular}

The atomic amount has been naturalized.

indicating that ethanol should have both promoting and inhibiting effects on pitting. Corrosion rate reached $9.77 \mathrm{~g} \mathrm{~m}^{-2} \mathrm{~h}$ in $5 \mathrm{M}$ ethanol, which was the highest case. While weight loss mitigated in $10 \mathrm{M}$ ethanol, corrosion rate was still much higher than in lower ethanol concentration solutions.

Figure 3 shows the surface profiles of samples immersed in acid ferric chloride solution with series of ethanol contents for $24 \mathrm{~h}$. With the increase of ethanol concentrations from 0 to $5 \mathrm{M}$, the quantities of pits increased, and the surface area of the single pit changed little. For samples in $10 \mathrm{M}$ ethanol, the surface of samples was densely covered with pits, and the areas of pits were much smaller, which was quite different from the pits pattern under $0 \mathrm{M}$ ethanol to $5 \mathrm{M}$ ethanol. As shown in Figure 4, the logarithm of the number of pits on the 
sample surface has a linear relationship with the concentration of ethanol. Such phenomenon can also be observed in methanolic solutions. In methanolic solutions, the change in pit density could be attributed to the oxidation from methanol to formic acid (Szklarska-Smialowska and Mankowski, 1982). However, similar mechanism cannot hold in ethanolic solution, since the oxidation from ethanol to acetic acid in acid medium takes place at $1.2 \mathrm{~V}$ (Tremiliosi-Filho et al., 1998), which is greater than the electrode potential of iron (III) toward iron (II) (771 mV vs. RHE). The mechanism of the effect of ethanol on the pits density will be discussed in section Discussion.

\section{Effect of Ethanol on Pitting Behavior of 316L Samples in Electrochemical Tests}

Figure 5 shows the polarization curves of $316 \mathrm{~L}$ samples in $1 \mathrm{M}$ $\mathrm{NaCl}$ solution with different ethanol contents at $30^{\circ} \mathrm{C}$. The breaking potential gradually decreased from 489 to $239 \mathrm{mV}$ with the addition of ethanol. In methanolic solutions, the dissolution of metal matrix in pits slows down due to the lower diffusion coefficient of metal cations (Ramgopal and Amancherla, 2012). Similar phenomenon occurred in the ethanolic solutions. At the rear stage after pits break down, the climb of current density got stuck in the ethanolic solutions. In $10 \mathrm{M}$ ethanol, the current density fell obviously during climbing, which shared the same climb behavior in multiple tests.

The derived corrosion potential $\left(E_{\text {corr }}\right)$, breakdown potential $\left(E_{b}\right)$ and the average passive current density $\left(i_{\text {pass }}\right)$ values are listed in Table 3. $E_{b}$ decreased significantly while $E_{\text {corr }}$ and $i_{\text {pass }}$ changed slightly as the concentration of ethanol increased. It proved that the pitting resistance of $316 \mathrm{~L}$ did deteriorate with no obvious change in passivation film. In addition, the dispersion of $E_{b}$ decreased with the increased ethanol content.

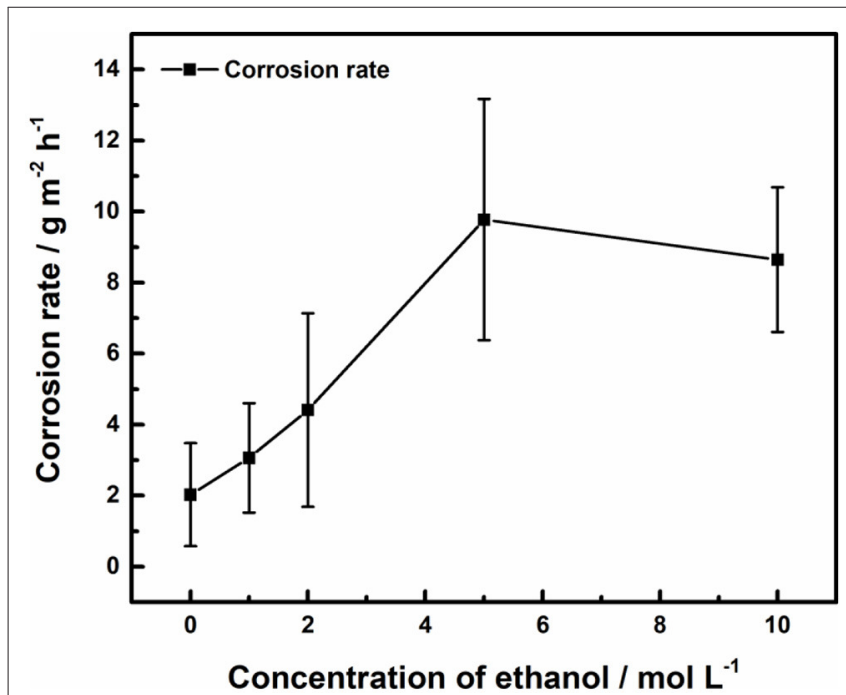

FIGURE 2 | Effect of ethanol on corrosion rate of 316L samples.

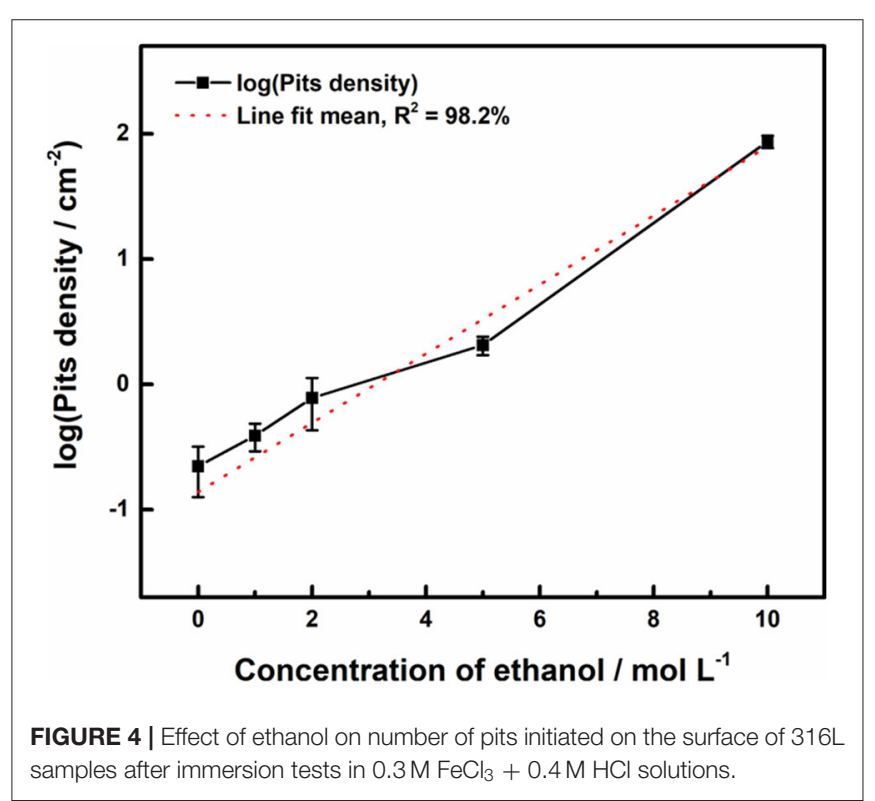

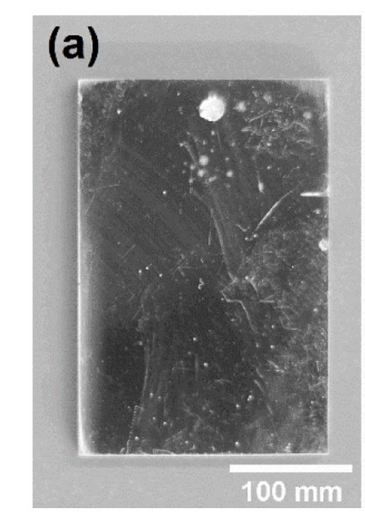
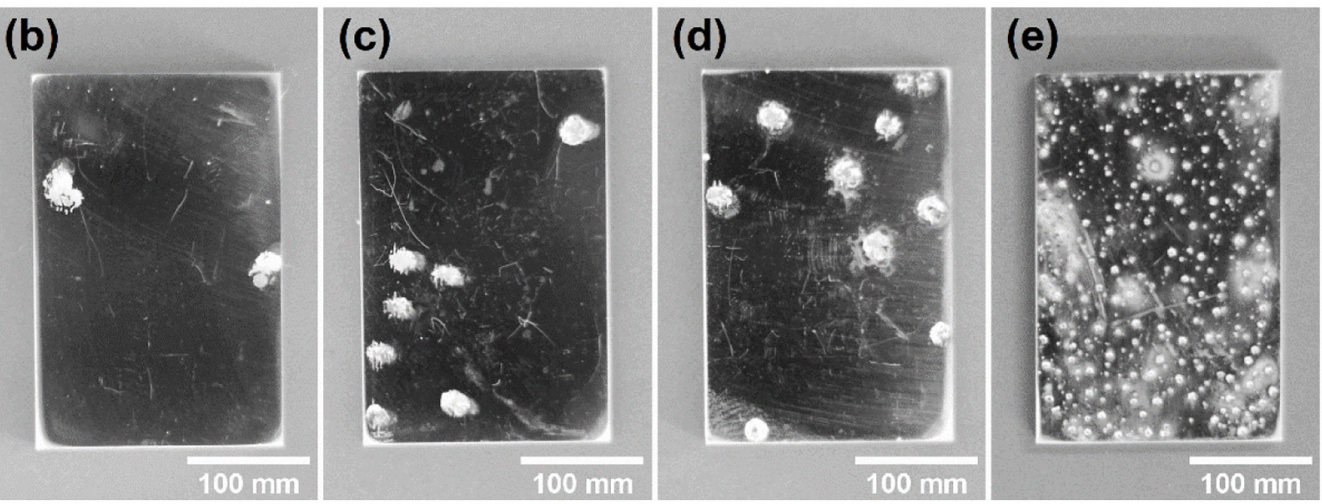

FIGURE 3 | Pits pattern of the 316 samples after 24-h immersion tests in $0.3 \mathrm{M} \mathrm{FeCl} 3+0.4 \mathrm{M} \mathrm{HCl} \mathrm{solutions} \mathrm{with} \mathrm{(a)} 0 \mathrm{M}$, (b) $1 \mathrm{M}$, (c) $2 \mathrm{M}$, (d) $5 \mathrm{M}$, (e) $10 \mathrm{M}$ ethanol. 


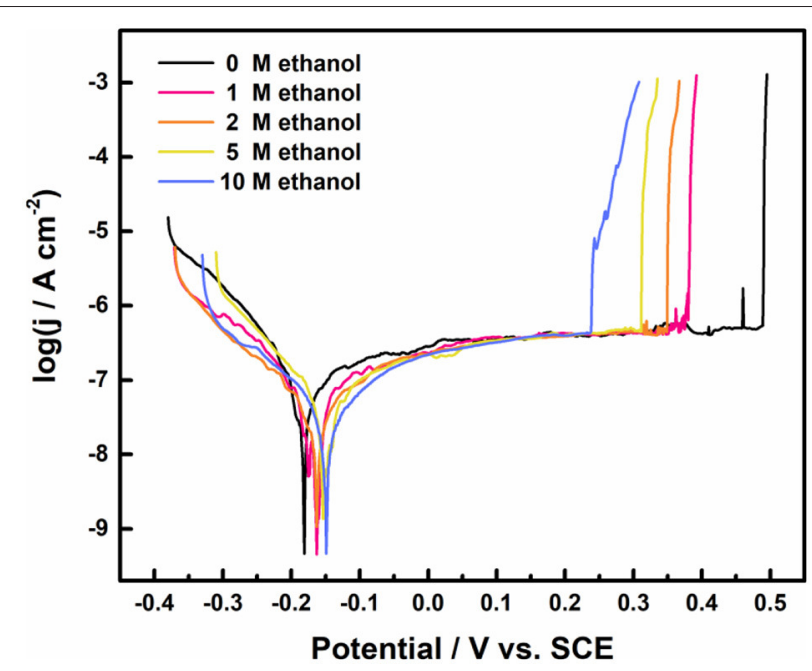

FIGURE 5 | The potentiodynamic polarization curves of 316L stainless steel samples in $1 \mathrm{M} \mathrm{NaCl}$ solution with different ethanol concentration, terminated at $1 \mathrm{~mA} \mathrm{~cm}-2$
TABLE 3 | Corrosion potential $\left(E_{c o r r}\right)$, breakdown potential $\left(E_{b}\right)$ and average passive current density (ipass) of $316 \mathrm{~L}$ stainless steel samples in solutions with different ethanol content.

\begin{tabular}{lccc}
\hline $\mathbf{C}_{\mathrm{EtOH}}\left(\mathbf{m o l ~ L}^{-\mathbf{1}}\right)$ & $\boldsymbol{E}_{\text {corr }}(\mathbf{m V})$ & $\boldsymbol{E}_{\boldsymbol{b}}(\mathbf{m V})$ & $\boldsymbol{i}_{\text {pass }}\left(\boldsymbol{\mu} \mathbf{A ~ c m}^{-\mathbf{2}}\right)$ \\
\hline 0 & $-180 \pm 22$ & $492 \pm 42$ & $0.45 \pm 0.02$ \\
1 & $-163 \pm 19$ & $369 \pm 36$ & $0.42 \pm 0.01$ \\
2 & $-162 \pm 20$ & $350 \pm 34$ & $0.43 \pm 0.01$ \\
5 & $-153 \pm 15$ & $321 \pm 27$ & $0.42 \pm 0.01$ \\
10 & $-149 \pm 19$ & $240 \pm 20$ & $0.42 \pm 0.01$ \\
\hline
\end{tabular}

The pits pattern on the surface of $316 \mathrm{~L}$ samples after potentiodynamic polarization tests was similar to the pattern in immersion tests. As shown in Figure 6, pits density increased as concentration of ethanol increased, but no exponential growth as in immersion tests occurred. Since the number of precursor sites on the surface of stainless steel is finite (Chen et al., 2020) and stable pits require enough time to incubate at lower overvoltage (Frankel et al., 1987), the reason for different trend from immersion experiments could be inadequate development time for activation of possible pits and deprivation of precursor sites.

As shown in Figure 7, panoramic optical micrographs of samples were taken and stitched after polarization tests. Many pits initiated on the surface of $316 \mathrm{~L}$ samples after the polarization test in $1 \mathrm{M} \mathrm{NaCl}$ solution with 0 and $10 \mathrm{M}$ ethanol terminated at $1 \mathrm{~mA} \mathrm{~cm}{ }^{-2}$. Considering Figure 5, the dissolution charge after broken in $0 \mathrm{M}$ ethanol was contributed by the single pit on the surface, which developed rapidly and generated higher current density. In $10 \mathrm{M}$ ethanol case, the dissolution charge was formed by the joint contribution of several pits. While most of the pits failed to grow up to the size of the main pits, several pits developed to scale, which suggested that single pit failed to generate sufficient current density, and instead, more pits

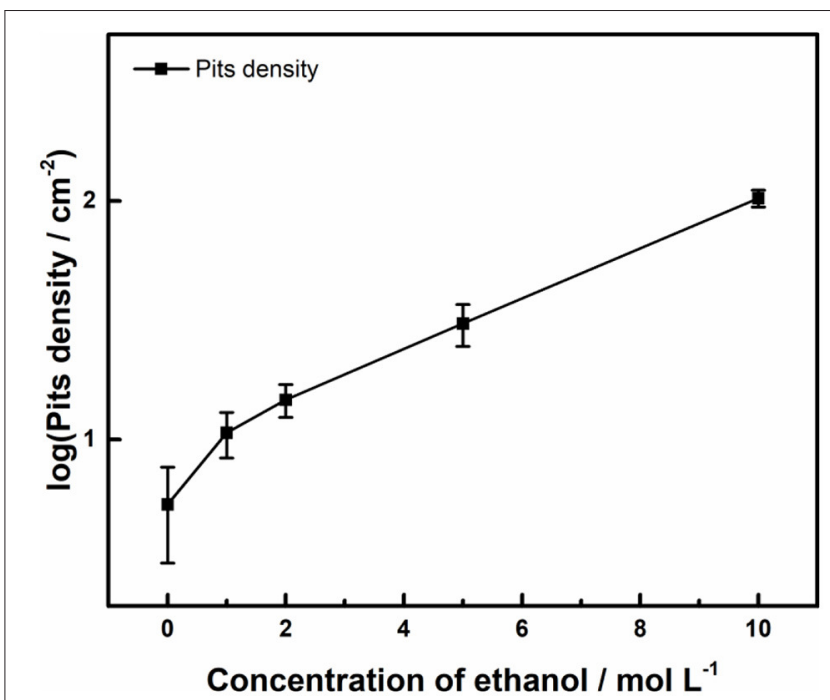

FIGURE 6 | Effect of ethanol on number of pits initiated on the surface of 316L after polarization tests in $1 \mathrm{M} \mathrm{NaCl}$ solution with different ethanol concentrations at $30^{\circ} \mathrm{C}$, terminated at $1 \mathrm{~mA} \mathrm{~cm}^{-2}$.

were initiated at a higher overvoltage to climb to the specified current density. It could be assumed that first single stable pit was generated at $\mathbf{E}_{\mathbf{b}}$, and multiple pits were nucleated before the current density reached $1 \mathrm{~mA} \mathrm{~cm}^{-2}$.

Since mass pits and the different dissolution charge developed hindered the observation of the developing behavior of single pits under the same conditions, $100 \mu \mathrm{A} \mathrm{cm}^{-2}$ as a lower termination current density was applied to obtain the morphology of a single pitting on the sample surface. As shown in Figure 8, pits on the surface of $316 \mathrm{~L}$ samples were limited to single. This confirms the previous assumption for first single stable pit at $\mathbf{E}_{\mathbf{b}}$. It is noteworthy that the lacy cover occurred in $10 \mathrm{M}$ ethanol. Lacy cover is generally considered to be affected by the aggressiveness of the solution in the pits. Distribution of metal cations in hemispherical pits controlled the dissolution of matrix near the surface of samples in aqueous environment (Ernst et al., 1997). In environment less aggressive, the inner surface of pits near matrix surface tends to oscillate between diffusion-control process and reaction-control process, and forms lacy cover.

The 3D plots in Figure 9, shows that the edge of the pits on the surface of stainless steel owned a lower contrast in ethanolic solution where the dissolved surfaces were steeper. It reveals that the bottom of it. The ratio of width and depth of pits in different concentrations of ethanol was calculated and summarized in Figure 10. Once ethanol was present, the depth of the pits would be significantly deeper than in non-ethanolic environment.

\section{DISCUSSION}

Based on the experiment results above, the effect of ethanol on the pitting behavior of stainless steel was clear. In ethanolic solutions, the initiation of pitting was simplified, the development was suppressed, and the pits tended to be deeper. 


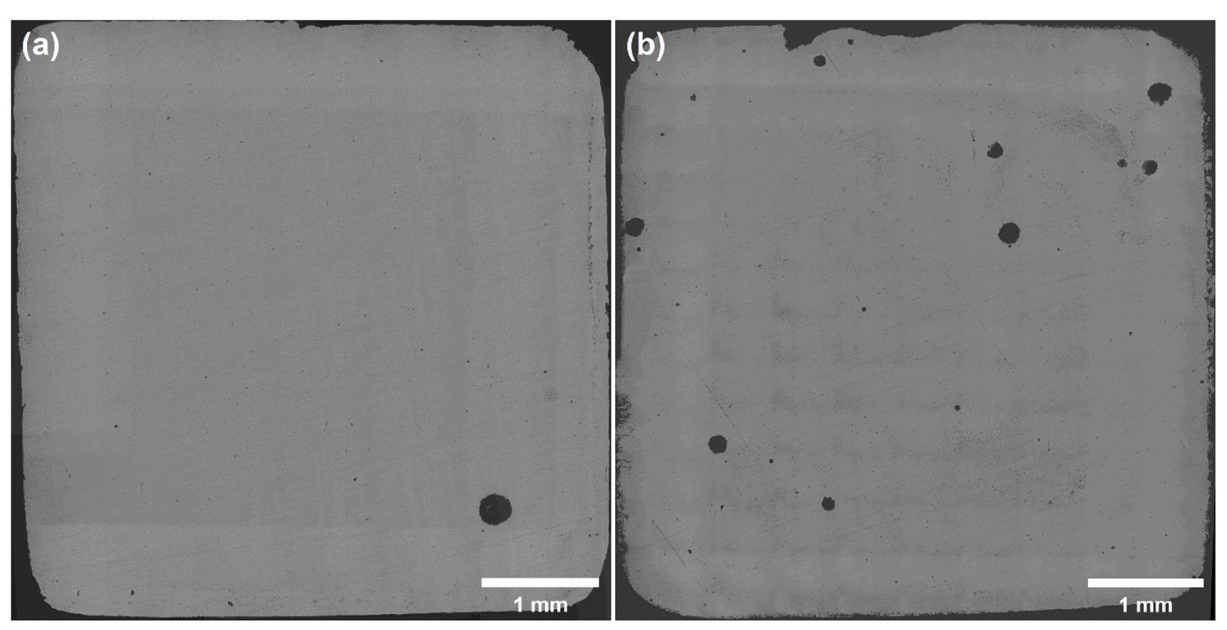

FIGURE 7 | Panoramic optical micrograph of sample surfaces after polarization tests in $1 \mathrm{M} \mathrm{NaCl}$ solution with (a) $0 \mathrm{M}$, (b) $10 \mathrm{M}$ ethanol at $30^{\circ} \mathrm{C}$, terminated at $1 \mathrm{~mA}$ $\mathrm{cm}^{-2}$. No ultrasound treatment was conducted.

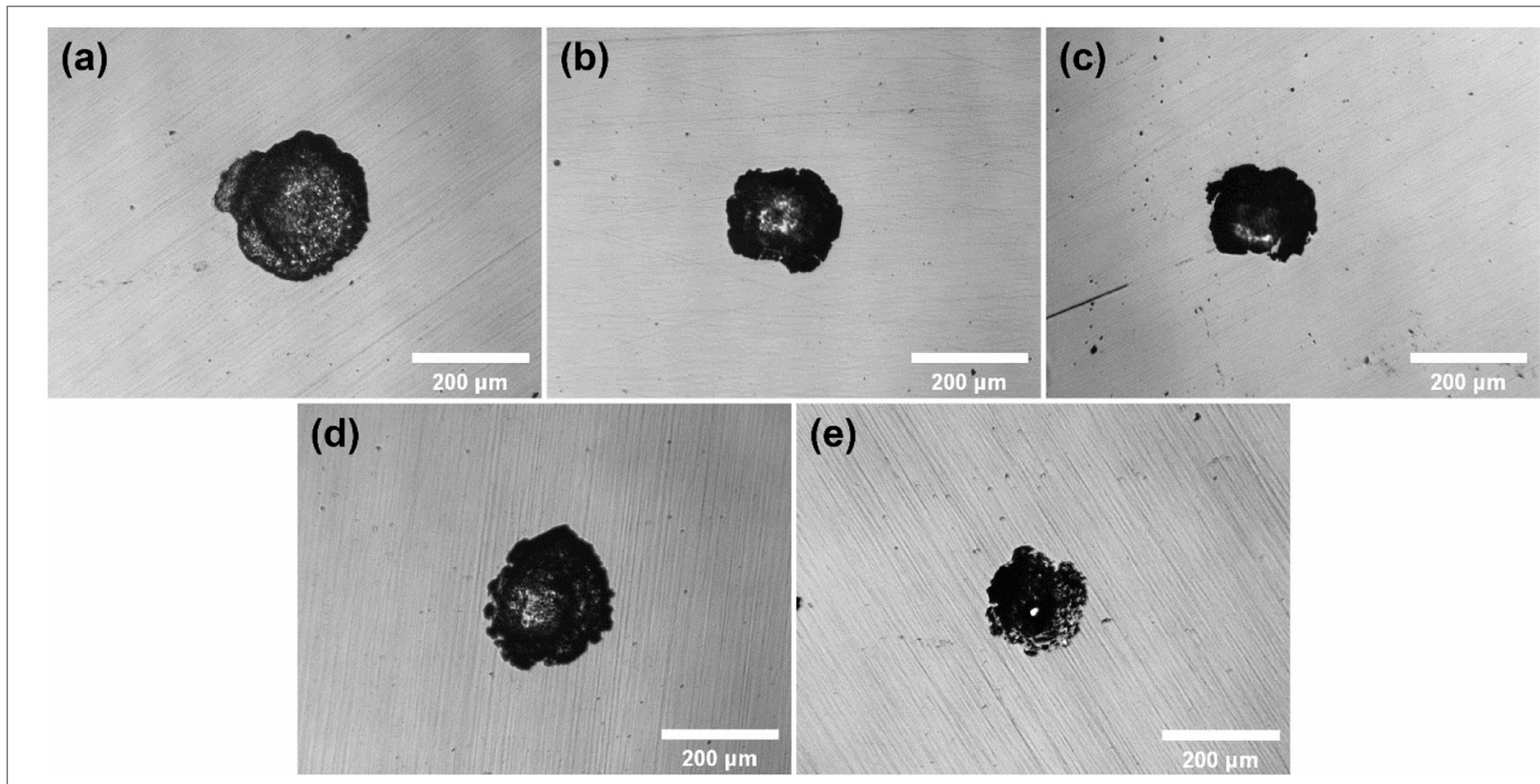

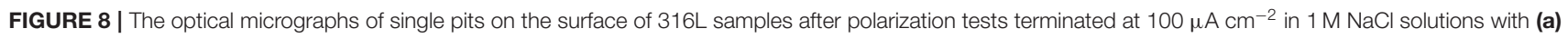
$0 \mathrm{M}$, (b) $1 \mathrm{M}$, (c) $2 \mathrm{M}$, (d) $5 \mathrm{M}$, (e) $10 \mathrm{M}$ ethanol.

Since the development of stable pits is an electrochemical process controlled by metal cation diffusion (Frankel et al., 2017) and the higher viscosity of ethanolic solution (Khattab et al., 2012), the drop of ions diffusion rate was ascribed to the inhabitation of pitting development. However, the influence on pits initiation is not caused by the deterioration of the passivation film on the surface of $316 \mathrm{~L}$ and the theory of alcohol electro-oxidation does not apply to ethanolic systems. Interpretations more suitable for this system need to be proposed.
Which has been neglected for a long time is that the introduction of ethanol results in the decrease of saturated metal cation concentration $\left(\mathrm{M}^{\mathrm{n}+}\right)$ at the bottom of pits. Ferrous ions are much less soluble in ethanol than in pure water (Pound, 1939). In addition, $\mathrm{pH}$ of solution has changed at the same metal cation concentration as the ethanol content increased. Ho et al. found that the decrease of the precipitation $\mathrm{pH}$ of the $\mathrm{Ni}(\mathrm{OH})_{2}$ as the ethanol content increased would enhance hydrolysis of metal cations, resulting in lower $\mathrm{pH}$ in ethanolic solutions (Ho and Van Zee, 2000). Based on those two works, schematic $\mathrm{pH}$ curves are 

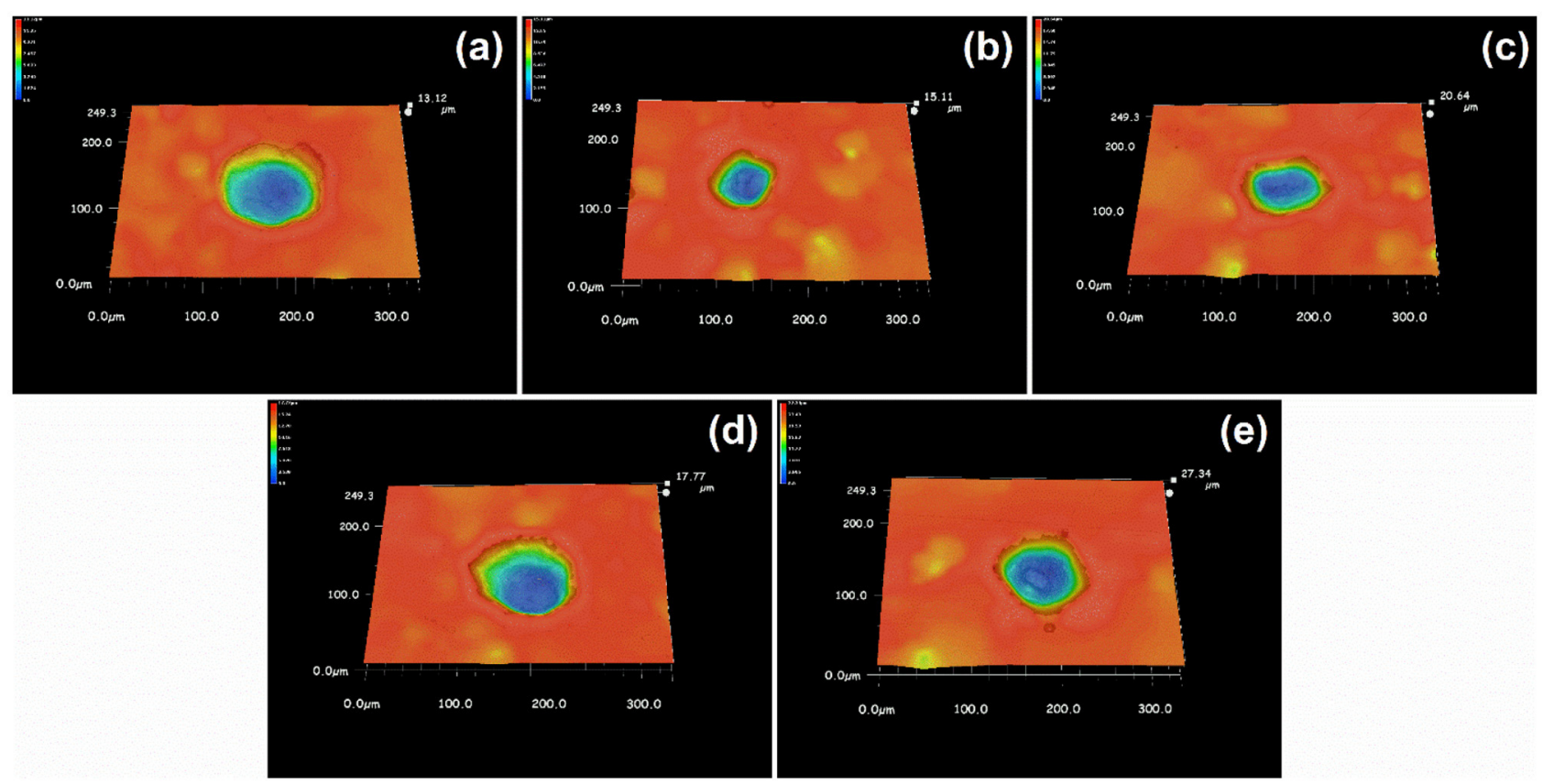

FIGURE 9 | The 3D profile of single pits after ultrasound treatment after polarization tests terminated at $100 \mu \mathrm{A} \mathrm{cm}-2$ in $1 \mathrm{M} \mathrm{NaCl} \mathrm{solutions} \mathrm{with} \mathrm{(a)} 0 \mathrm{M}$, (b) $1 \mathrm{M}$, (c) $2 \mathrm{M}$, (d) $5 \mathrm{M}$, (e) $10 \mathrm{M}$ ethanol.

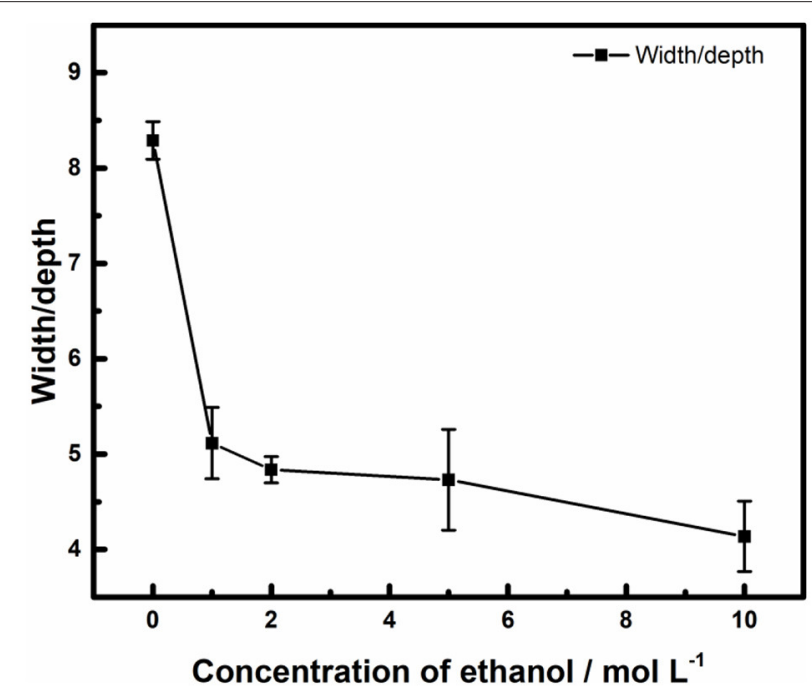

FIGURE 10 | Effect of ethanol on the ratio of width and depth of pits on the surface of $316 \mathrm{~L}$ samples after polarization tests terminated at $100 \mu \mathrm{A} \mathrm{cm}^{-2}$.

illustrated as Figure 11, where $\mathrm{pH}_{\text {crit }}$ is the $\mathrm{pH}$ dissolves iron under a specified potential in the pourbaix diagrams for iron (Beverskog and Puigdomenech, 1996). When the concentration of $\mathrm{M}^{\mathrm{n}+}$ is far from saturation, which is similar to the solution in pits during pitting initiation, the $\mathrm{pH}$ of solutions decreases as the ethanol content increases. When the $\mathrm{M}^{\mathrm{n}+}$ is saturated, which is similar to the solution at the bottom of pits during pitting

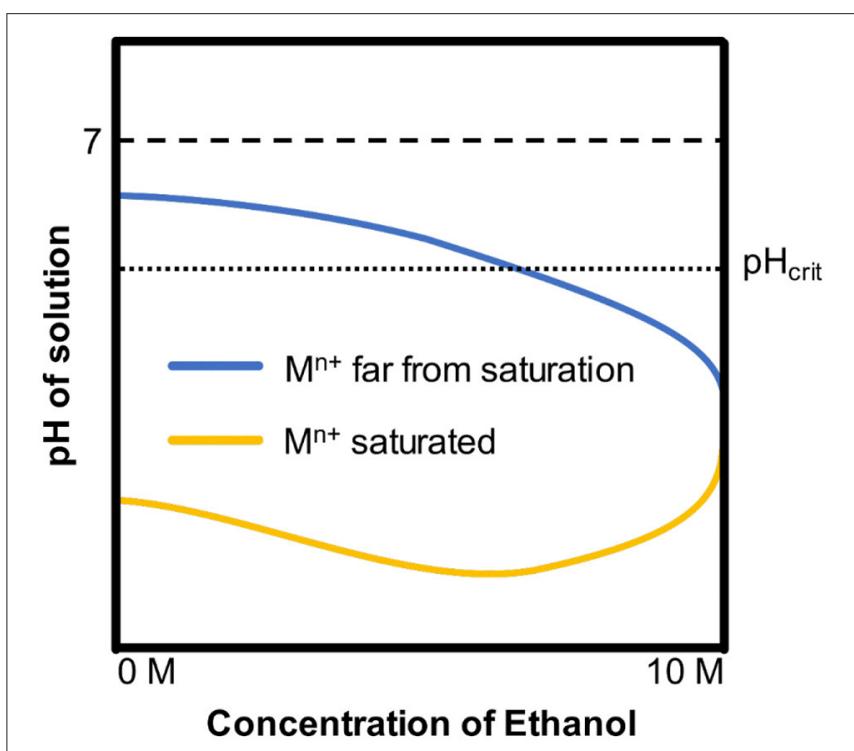

FIGURE 11 | The schematic pH curves induced by hydrolysis of metal cations $\left(\mathrm{Ni}^{2+}, \mathrm{Fe}^{2+}, \mathrm{Fe}^{3+}\right.$ etc. $)$ in water with different ethanol contents.

developments, as a result of the synergy effect of hydrolysis enhancement and solubility reduction, the $\mathrm{pH}$ of solutions first decreases then increases.

According to the schematic $\mathrm{pH}$ curves, schematic diagram of pitting initialization in ethanolic solutions and non-ethanolic solutions is described as Figure 12A. The metastable pits start with the injection of chloride ions and come into a void (Frankel 


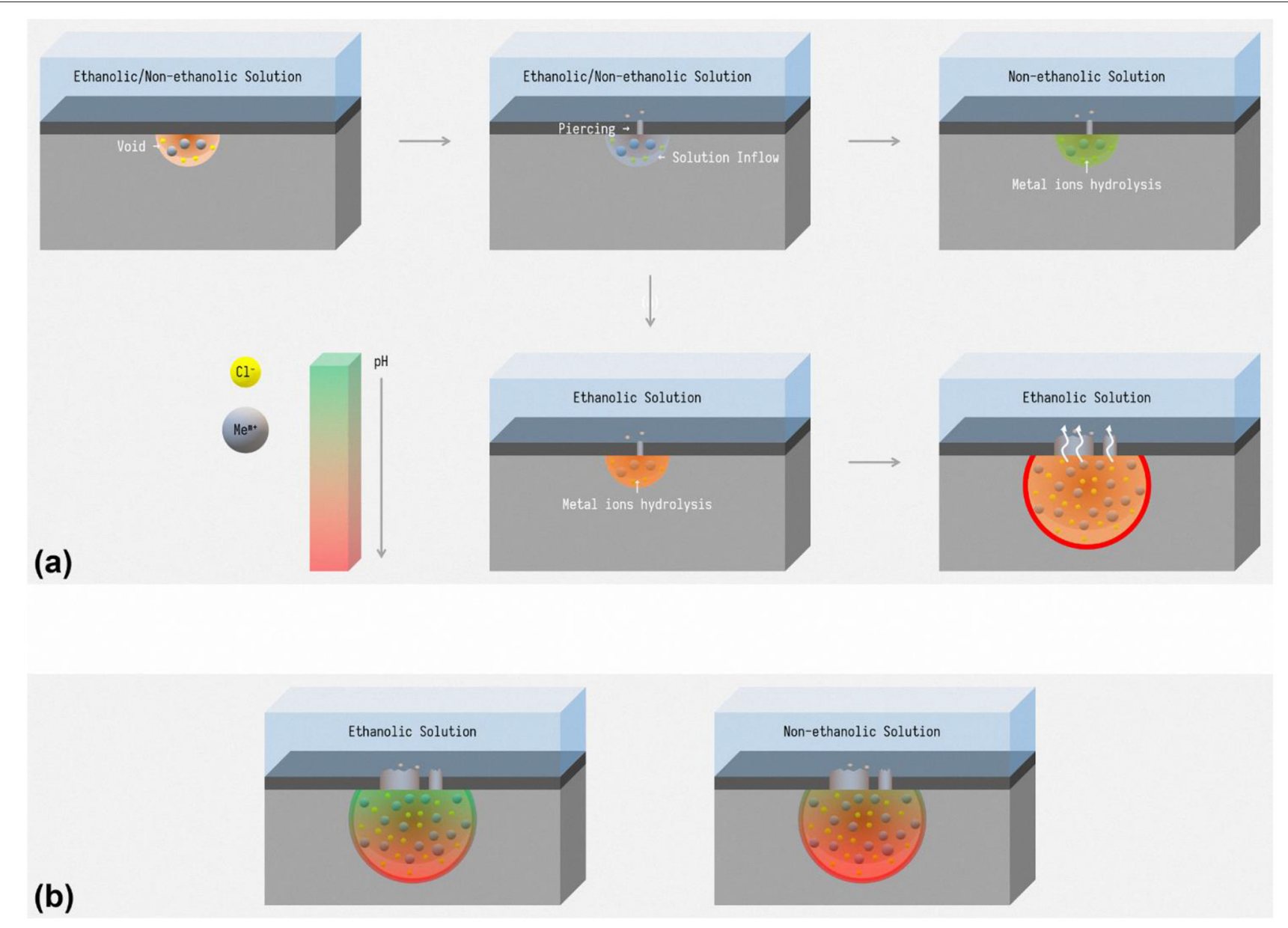

FIGURE 12 | The schematic diagram of (a) pitting initialization, (b) pH distribution in pits, in ethanolic solutions and non-ethanolic solutions.

et al., 1987). Since the performance of passive films changed slightly and ethanol does not affect the puncture behavior of chloride ions, the probabilities of this event are the same whether ethanol is introduced. Along with the expansion of the void, solutions inflow and contact the substrate and the difference of hydrolysis influences the result of pits initiation. The medium in ethanolic solutions have stronger acidity while $\mathrm{pH}$ of the medium in non-ethanolic solution failed to dissolve the matrix and the pits annihilated. As a result, pits are more easily activated in ethanolic solutions. Therefore, during the immersion tests, more pitting occurred on the surface of stainless steel in the ethanolic environment.

In addition, the synergy effect of metal cation solubility drop and hydrolysis enhancement is also ascribed to the morphology difference in ethanolic solutions. In stable pitting, a salt film forms on the inner surface of pits due to saturation of metal cations (Frankel, 1998). According to the yellow curve in Figure 11, the $\mathrm{pH}$ at the bottom of pits is higher in ethanolic solutions. As shown in Figure 12B, the concentration of metal cations at the bottom of pits is lower in high ethanol content than in non-ethanolic solution, resulting in dissatisfaction of $\mathrm{pH}$ to $\mathrm{pH}_{\text {crit }}$ near the surface. This leads to less dissolution at the top and more dissolution at the bottom of pitting in alcoholic solution, resulting in lacy cover and steeper pits. This feature also helped to understand the difference of pits pattern in $10 \mathrm{M}$ ethanol immersion test. For sites in certain hemisphere pits, the current density of metal cations dissolution out of the pit could be approximated by Li et al. (2018).

$$
i_{\text {diff }, \text { site }}=\frac{3 n F D C_{\text {site }}}{2 \pi r}
$$

where $n$ is the average oxidation state of the metal cations, $F$ is the Faraday constant, $D$ is the effective diffusivity of the metal cations, $C_{\text {site }}$ is the concentration of metal cations at the site, and $r$ is the radius of the hemispherical pit. At the same time, the dissolution electric quantity of metal cations is given by

$$
Q_{\text {diff } f \text { site }}=\int I_{\text {diff,site }} t d t=\int i_{\text {diff,site }} S t d t
$$

where $t$ is the diffusion time range from pitting initiation to end of tests, and $S$ is the effective area of pits, which considers the effect of lacy cover. Diffusivity of the metal cations decreases with 
the concentration of ethanol. The effect of lacy cover narrows the $S$ value and slows down the rate of loss of ions from the pit. Under the suppress of diffusivity and $S$ value, the size of pits in high concentration of ethanol are limited to a small scale.

\section{CONCLUSION}

In this work, the effects of ethanol on the passive film, pitting behavior and pits morphology have been investigated with XPS analysis, immersion tests, potentiodynamic polarization tests and $3 \mathrm{D}$ microscope. The change in pitting behavior is due to hydrolysis enhancement and diffusion inhibition of metal cations in the ethanolic solutions. The effect of ethanol on the metal oxide content in the passive film on the surface of $316 \mathrm{~L}$ stainless steel in borate buffer solution is slight. The corrosion rate of $316 \mathrm{~L}$ stainless steel first increased then decreased while the initiation of pits is facilitated. The pitting potential of 316L stainless steel samples in $1 \mathrm{M} \mathrm{NaCl}$ solutions decreased from 489 to $239 \mathrm{mV}$ with the gradual addition of ethanol. When the polarization curve was interrupted in the early stage of the pitting development to preserve single-pit pattern, the

\section{REFERENCES}

Abel, J., and Virtanen, S. (2015). Corrosion of martensitic stainless steel in ethanolcontaining gasoline: influence of contamination by chloride, $\mathrm{H} 2 \mathrm{O}$ and acetic acid. Corros. Sci. 98, 318-326. doi: 10.1016/j.corsci.2015.05.027

Beavers, J. A., Gui, F., and Sridhar, N. (2011). Effects of environmental and metallurgical factors on the stress corrosion cracking of carbon steel in fuelgrade ethanol. Corrosion 67, 025005-1-025005-15. doi: 10.5006/1.3553341

Beverskog, B., and Puigdomenech, I. (1996). Revised pourbaix diagrams for iron at 25-300 ${ }^{\circ}$ C. Corros. Sci. 38, 2121-2135. doi: 10.1016/S0010-938X(96)00067-4

Bisht, B., Bhandari, H., Ruhi, G., Gairola, S. P., and Dhawan, S. K. (2017). Evaluation of an advanced self healing and highly durable corrosion protective epoxy coating modified with poly (Aniline-coPentafluoroaniline)/ZrO2 nanocomposite on mild steel. Curr. Smart Mater. 2, 130-145. doi: 10.2174/2405465802666170707163408

Calabrese, L., Bruzzaniti, P., and Proverbio, E. (2018). Pitting corrosion of aluminum alloys in anhydrous ethanol. Mater. Corros. 69, 1815-1826. doi: 10.1002/maco.201810125

Chen, B., Sun, Y., Cai, D., Yao, Q., Yin, L., Wan, Y., et al. (2020). Use of the potentiostatic pulse technique to study and influence pitting behavior of $317 \mathrm{~L}$ stainless steel. J. Electrochem. Soc. 167:041509. doi: 10.1149/1945-7111/ab7983

de Anna, P. L. (1985). The effects of water and chloride ions on the electrochemical behaviour of iron and 3041 stainless steel in alcohols. Corros. Sci. 25, 43-53. doi: 10.1016/0010-938X(85)90087-3

Designation, A. (2009). Standard Test Methods for Pitting and Crevice Corrosion Resistance of Stainless Steels and Related Alloys by Use of Ferric Chloride Solution. ASTM International.

Ekilik, V. V., and Grigor'ev, V. P. (2002). Metal corrosion in organic and aqueousorganic media. Prot. Metals 38, 124-131. doi: 10.1023/A:1014960915029

Ernst, P., Laycock, N. J., Moayed, M. H., and Newman, R. C. (1997). The mechanism of lacy cover formation in pitting. Corros. Sci. 39, 1133-1136.

Ferreira, E. A., Della Noce, R., Fugivara, C. S., and Benedetti, A. V. (2013). Influence of ethanol, acidity and chloride concentration on the corrosion resistance of AISI 316L stainless steel. J. Braz. Chem. Soc. 24, 397-405. doi: 10.5935/0103-5053.20130052

Frankel, G. S. (1998). Pitting corrosion of metals a review of the critical factors. J. Electrochem. Soc. 145, 2186-2198.

Frankel, G. S., Li, T., and Scully, J. R. (2017). Perspective-localized corrosion: passive film breakdown vs pit growth stability. J. Electrochem. Soc. 164:C180. doi: $10.1149 / 2.1381704$ jes decrease in width-depth ratio of pits in ethanolic solutions could be observed.

\section{DATA AVAILABILITY STATEMENT}

The raw data supporting the conclusions of this article will be made available by the authors, without undue reservation.

\section{AUTHOR CONTRIBUTIONS}

YW drafted the manuscript. YS and LY reviewed and revised the manuscript. DC, ND, LL, YJ, and JL provided comments and suggestions. All authors contributed to the article and approved the submitted version.

\section{FUNDING}

This work was supported by National Natural Science Foundation of China (Grant No. 5190146) and China Postdoctoral Science Foundation (Grant No. 2018M632016).

Frankel, G. S., Stockert, L., Hunkeler, F., and Boehni, H. (1987). Metastable pitting of stainless steel. Corrosion 43, 429-436.

Gui, F., Sridhar, N., and Beavers, J. A. (2010). Localized corrosion of carbon steel and its implications on the mechanism and inhibition of stress corrosion cracking in fuel-grade ethanol. Corrosion 66, 125001-125001-12. doi: 10.5006/1.3524831

Ho, C.-H., and Van Zee, J. W. (2000). Effect of Ethanol and Temperature on the Hydrolysis of a Nickel(II) Ion in Ethanol-Water Solutions. Ind. Eng. Chem. Res. 39, 752-758. doi: 10.1021/ie9702789

Hronsky, P. (1981). Corrosion behavior of metallic materials in organic media containing hydrogen chloride. Corrosion 37, 161-170. doi: 10.5006/1.3622160

Hronsky, P., and Duquette, D. J. (1982). Pitting behavior of duplex 308L stainless steel in methanol/water/HCl solutions. Corrosion 38, 63-69. doi: 10.5006/1.3577327

$\mathrm{Hu}, \mathrm{E} ., \mathrm{Xu}, \mathrm{Y} ., \mathrm{Hu}, \mathrm{X} ., \mathrm{Pan}, \mathrm{L}$. , and Jiang, S. (2012). Corrosion behaviors of metals in biodiesel from rapeseed oil and methanol. Renew. Energy 37, 371-378. doi: 10.1016/j.renene.2011.07.010

Kahyarian, A., Schumaker, A., Brown, B., and Nesic, S. (2017). Acidic corrosion of mild steel in the presence of acetic acid: mechanism and prediction. Electrochim. Acta 258, 639-652. doi: 10.1016/j.electacta.2017.11.109

Kelly, R. G., and Moran, P. J. (1990). The passivity of metals in organic solutions. Corros. Sci. 30, 495-509. doi: 10.1016/0010-938X(90)90053-8

Khattab, I. S., Bandarkar, F., Fakhree, M. A. A., and Jouyban, A. (2012). Density, viscosity, and surface tension of water+ethanol mixtures from 293 to $323 \mathrm{~K}$. Korean J. Chem. Eng. 29, 812-817. doi: 10.1007/s11814-011-0239-6

Lee, J., ye, Li, P., Lee, J., Ryu, H. J., and Oh, K. K. (2013). Ethanol production from Saccharina japonica using an optimized extremely low acid pretreatment followed by simultaneous saccharification and fermentation. Bioresour. Technol. 127, 119-125. doi: 10.1016/j.biortech.2012. 09.122

Lei, L., Sun, Y., Wang, X., Jiang, Y., and Li, J. (2020). Strategies to enhance corrosion resistance of $\mathrm{Zn}$ electrodes for next generation batteries. Front. Mater. 7:96. doi: 10.3389/fmats.2020.00096

Li, T., Scully, J. R., and Frankel, G. S. (2018). Localized corrosion: passive film breakdown vs pit growth stability: Part II. A model for critical pitting temperature. J. Electrochem. Soc. 165, C484-C491. doi: 10.1149/2.059 1809 jes

Lou, X., and Singh, P. M. (2010). Role of water, acetic acid and chloride on corrosion and pitting behaviour of carbon steel in fuel-grade ethanol. Corros. Sci. 52, 2303-2315. doi: 10.1016/j.corsci.2010.03.034 
Lou, X., Yang, D., and Singh, P. M. (2010). Film breakdown and anodic dissolution during stress corrosion cracking of carbon steel in bioethanol. J. Electrochem. Soc. 157, C86-C94. doi: 10.1149/1.3269927

Newman, R. C. (2008). Review and hypothesis for the stress corrosion mechanism of carbon steel in alcohols. Corrosion 64, 819-823. doi: 10.5006/1.3279915

Okamoto, G., and Shibata, T. (1970). Stability of passive stainless steel in relation to the potential of passivation treatment. Corros. Sci. 10, 371-378.

Pound, J. R. (1939). The oxidation of solutions of ferrous chloride in alcohols. J. Phys. Chem. 43, 969-980. doi: 10.1021/j150395a002

Radi, P. A., Vieira, A., Manfroi, L., de Nass, K. C. F., Ramos, M. A. R., Leite, P., et al. (2019). Tribocorrosion and corrosion behavior of stainless steel coated with DLC films in ethanol with different concentrations of water. Ceram. Int. 45, 9686-9693. doi: 10.1016/j.ceramint.2019. 02.103

Ramgopal, T., and Amancherla, S. (2012). Role of methanol on pitting of type 316 stainless steel. Corrosion 61, 1136-1144. doi: 10.5006/1.3278150

Rocha, G. J. M., Gonçalves, A. R., Oliveira, B. R., Olivares, E. G., and Rossell, C. E. V. (2012). Steam explosion pretreatment reproduction and alkaline delignification reactions performed on a pilot scale with sugarcane bagasse for bioethanol production. Indus. Crops Prod. 35, 274-279. doi: 10.1016/j.indcrop.2011.07.010

Saito, H., Shibata, T., and Okamoto, G. (1979). The inhibitive action of bound water in the passive film of stainless steel against chloride corrosion. Corros. Sci. 19, 693-708.

Samide, A., Tutunaru, B., Moantăa, A., Ionescu, C., Tigae, C., and Vladu, A.-C. (2015). A study of the surface protective layer formed on carbon steel in water-dioxane solution containing $0.15 \mathrm{M} \mathrm{NaCl}$ in presence of an azo dye with antimicrobial activity. Int. J. Electrochem. Sci. 10, 4637-4653. Available online at: https://apps.webofknowledge.com/full_ record.do?product $=$ UA\&search_mode $=$ GeneralSearch\&qid $=1 \&$ SID $=$ 6DDtpF7PvvEGB8narYU\&page $=1 \&$ doc $=1$

Samusawa, I., and Shiotani, K. (2015). Influence and role of ethanol minor constituents of fuel grade ethanol on corrosion behavior of carbon steel. Corros. Sci. 90, 266-275. doi: 10.1016/j.corsci.2014.10.020

Sarkar, N., Ghosh, S. K., Bannerjee, S., and Aikat, K. (2012). Bioethanol production from agricultural wastes: an overview. Renew. Energy 37, 19-27. doi: $10.1016 /$ j.renene.2011.06.045

Shchukarev, S. A., and Tolmacheva, T. A. (1968). Solubility of oxygen in ethanol-Water mixtures. J. Struct. Chem. 9, 16-21. doi: 10.1007/BF00 744018
Soriano, C., and Alfantazi, A. (2016). Corrosion behavior of galvanized steel due to typical soil organics. Constr. Build. Mater. 102, 904-912. doi: 10.1016/j.conbuildmat.2015.11.009

Sun, Y., Liu, X., Jiang, Y., Li, J., Ding, J., Hu, W., et al. (2019). Recent advances and challenges in divalent and multivalent metal electrodes for metal-air batteries. J. Mater. Chem. A 7, 18183-18208. doi: 10.1039/C9TA05094A

Szklarska-Smialowska, Z., and Mankowski, J. (1982). The pitting of stainless steel in water-containing methanol. Corros. Sci. 22, 1105-1112.

Torkkeli, J., Saukkonen, T., and Hänninen, H. (2015). Effect of MnS inclusion dissolution on carbon steel stress corrosion cracking in fuel-grade ethanol. Corros. Sci. 96, 14-22. doi: 10.1016/j.corsci.2015.03.002

Torsner, E. (2010). Solving corrosion problems in biofuels industry. Energy Mater. 5, 42-48. doi: 10.1179/147842209X12579401586726

Tremiliosi-Filho, G., Gonzalez, E. R., Motheo, A. J., Belgsir, E. M., Léger, J.M., and Lamy, C. (1998). Electro-oxidation of ethanol on gold: analysis of the reaction products and mechanism. J. Electroanal. Chem. 444, 31-39. doi: 10.1016/S0022-0728(97)00536-6

Wang, F., Chen, G., Zhang, N., Liu, X., and Ma, R. (2019). Engineering of carbon and other protective coating layers for stabilizing silicon anode materials. Carbon Energy 1, 219-245. doi: 10.1002/cey2.24

Wang, J.-B., Wang, J.-M., Shao, H.-B., Zhang, J.-Q., and Cao, C.-N. (2007) The corrosion and electrochemical behaviour of pure aluminium in alkaline methanol solutions. J. Appl. Electrochem. 37, 753-758. doi: 10.1007/s10800-007-9310-8

Wang, L., Gao, H., Fang, H., Wang, S., and Sun, J. (2016). Effect of methanol on the electrochemical behaviour and surface conductivity of niobium carbidemodified stainless steel for DMFC bipolar plate. Int. J. Hydrogen Energy 41, 14864-14871. doi: 10.1016/j.ijhydene.2016.07.037

Conflict of Interest: The authors declare that the research was conducted in the absence of any commercial or financial relationships that could be construed as a potential conflict of interest.

Copyright (C) 2020 Wan, Sun, Cai, Yin, Dai, Lei, Jiang and Li. This is an open-access article distributed under the terms of the Creative Commons Attribution License (CC $B Y)$. The use, distribution or reproduction in other forums is permitted, provided the original author(s) and the copyright owner(s) are credited and that the original publication in this journal is cited, in accordance with accepted academic practice. No use, distribution or reproduction is permitted which does not comply with these terms. 